\title{
Dilemas y desafíos de la política habitacional argentina desde un enfoque de derechos*
}

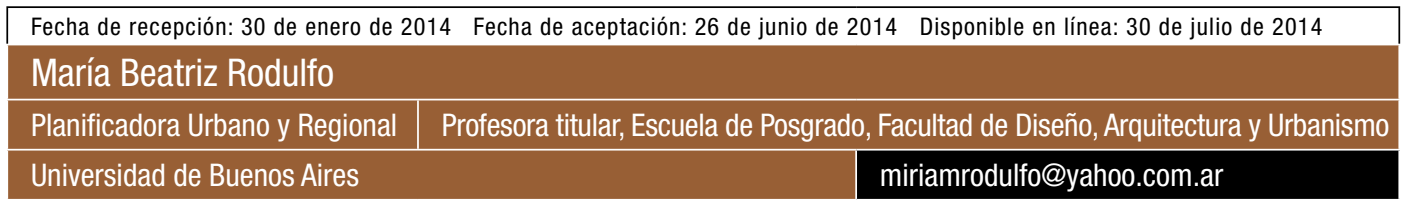

Teresa Boselli

Arquitecta Profesora adjunta e investigadora Facultad de Diseño, Arquitectura y Urbanismo

Universidad de Buenos Aires

tbosel@fadu.uba.ar

Resumen Las políticas habitacionales latinoamericanas instaladas en el siglo XX de la mano del Estado de bienestar, perfilaron estrategias de "activación de la oferta constructora" para atender las demandas masivas de urbanización e industrialización. Dicho modelo de intervención pública directa no alcanzó sustentabilidad, por lo que evolucionó hacia modelos de "activación de la demanda" y desplazó el agente motor hacia el sistema financiero y el mercado. Ambos modelos refuerzan la perspectiva sectorial vinculada más al crecimiento económico que a la inclusión social. Argentina ha mantenido la orientación inicial. El Sistema Fonavi y la Política Federal de Vivienda operan hasta nuestros días como herramienta político-técnica de gobernabilidad y de reactivación económica frente a las crisis socioeconómicas recurrentes. Ante un déficit habitacional que persiste, el artículo interroga sobre la deseabilidad de sostener los actuales rumbos e identifica los dilemas y desafíos presentes desde un enfoque de derechos.

Palabras clave

\section{Derechos; inclusión social; política habitacional}

Artículo de reflexión, resultado de investigaciones realizadas en los últimos años como docentes e investigadoras de la Universidad de Buenos Aires y miembros invitados de la Red EPHA (Red de estudios sobre política habitacional argentina), en el marco del proyecto PICT Redes, acreditado por la Agencia Nacional de Promoción, Científica y Tecnológica de Argentina.

Cómo citar este artículo: Rodulfo, M. B. y Boselli, T. (2014). Dilemas y desafíos de la política habitacional argentina desde un enfoque de derechos. Cuadernos de Vivienda y Urbanismo, 7(14), 218-241. http://dx.doi.org/10.11144/Javeriana.CVU7-14.ddph 


\section{Dilemmas and Challenges of Argentina's Housing Policy from a Rights Approach}

Abstract Latin American housing policies, installed at mid-twentieth century promoted by the Welfare State, outlined "activation of constructive offer" strategies to attend the massive demands of urbanization and industrialization. This model of direct public intervention didn't achieve sustainability evolving to models of "demand activation", displacing the motor agent to the financial system and the market. Both models reinforce sectorial perspective linked to economic growth than social inclusion. Argentina has kept the following initial guidance. Fonavi's System and Federal Housing Policy operates today as a political-technical tool of governance and economic recovery facing recurrent socio-economic crisis. Facing a housing deficit that persists, the article questions about the desirability of sustaining current directions and identifies the dilemmas and challenges presents from a rights approach.

Keywords Rights; social inclusion; housing policy

\section{Dilemas e desafios da política habitacional argentina de uma abordagem de direitos}

Resumo As políticas habitacionais latino-americanas, instaladas na metade do século XX pelo Estado de Bem-estar social, incentivaram estratégias de "ativação da proposta construtiva" para atender à enorme demanda dos processos de urbanização e industrialização. Este modelo de intervenção pública direta não conseguiu atingir sustentabilidade, evoluindo para modelos de "ativação de demanda" mudando o motor agente á sistema financeiro e ao mercado. Ambos modelos reforçam a perspectiva setorial ligada mais ao crescimento econômico que à inclusão social. Argentina tem mantido a orientaçáo inicial. O Sistema Fonavi e a política de habitação Federal funcionam até os dias atuais como instrumento político-técnico de governabilidade e de reativação econômica na frente da crise sócio-econômica recorrentes. Diante de uma escassez de habitação que persiste, o artigo questiona a conveniência de manter os rumos atuais e identifica os dilemas e desafios presentes desde um enfoque de Direitos.

Palavras chave Direitos; inclusão social; política habitacional 


\section{Introducción}

Las políticas habitacionales en América Latina, instaladas en el siglo XX de la mano de la construcción del Estado de bienestar, perfilaron estrategias de activación de la oferta para atender las demandas sociales emergentes de los procesos de urbanización e industrialización y acompañar la instalación de los derechos sociales en la región. La institucionalización del ahorro obligatorio (impuesto al trabajo) utilizado como seguro social destinado a la vivienda, la conformación de fondos públicos dirigidos a la construcción habitacional masiva y la transferencia del capital social mediante el crédito subsidiado fueron las características centrales. Dichas estrategias no alcanzaron sustentabilidad, por lo que evolucionaron hacia sistemas de activación de la demanda que reemplazaron al agente motor desde el sistema productivo, al sistema financiero y al mercado. Ambas iniciativas caracterizan una actuación sectorial vinculada al crecimiento económico en una visión alejada de la perspectiva del desarrollo sin avanzar hacia objetivos de inclusión social y de ejercicio pleno del derecho a la vivienda.

La República argentina ha sostenido la orientación inicial, con intervención pública directa en una esfera de producción del satisfactor vivienda social, "fuera del mercado" que, en su operacionalización, vincula a las empresas constructoras y al Estado 'por medio de metas de activación de la oferta, generación de empleo e impacto multiplicador para otorgarle el doble rol de política social y macroeconómica.
La evolución del marco legal ha ido perfeccionándose en la administración de recursos con variaciones en los modos de articulación de la gestión pública, en pos de una mejor respuesta a la problemática sociohabitacional. Desde la creación del Fondo Nacional de la Vivienda (Fonavi) se instaló un sistema de actuación y producción de escala nacional, vigente hasta nuestros días, a pesar de las evaluaciones que recomiendan su reemplazo. El Sistema se ha mostrado hábil por constituir una eficaz herramienta político-técnica de gobernabilidad federal que produce empleo diversificado y reactivación económica a lo largo y ancho del país, en respuesta a escenarios recurrentes de crisis socioeconómicas y por ello, es valorado en los ámbitos político y social.

Desde 2003, esta valoración y las facilidades construidas por la gestión institucionalizada fueron utilizadas por el Poder Ejecutivo Nacional (PEN) en una nueva estrategia, la Política Federal de Vivienda (PFV), instrumentada como parte de las acciones movilizadoras para superar la crisis de "gobernabilidad política" y "emergencia económica y social" del principio de la década. La PFV, ubicada en el centro de la agenda social, se ha proyectado al impulso del despliegue de la obra pública y de aportes "no reintegrables" ${ }^{1}$ (subsidios) utilizados como herramientas técnico-políticas de la intervención nacional que, han dado continuidad a las directrices operacionales aun después de los cambios presidenciales del 2007 y 2011.

1 Asignación de recursos por el Área Urbanismo y Vivienda, provenientes del presupuesto nacional; tracción de recursos Fonavi del Sistema Federal de Vivienda por la Ley 24.464 y fideicomisos de fondos de pensión del Sistema Nacional de Seguridad Social (Anses). 
En 2013 se evidenciaron, por una parte, los alcances logrados que dieron cuenta del esfuerzo realizado, en relación con la mayor inversión y producción habitacional, reflejados en el crecimiento sectorial y en las expectativas sociales crecientes. Por otro lado, los límites económicos e institucionales interrogan sobre las vulnerabilidades que amenazan su sostenibilidad, mientras los aportes contradictorios, desde un enfoque de derechos, abren un debate para revisar los avances que proveen. Se entiende la política pública desde un enfoque de derechos como "la articulación racional de acciones y omisiones del Estado y sus resultados orientada a la realización de derechos de la población y basadas en : a) las obligaciones contraídas voluntariamente por los Estados a través de distintos instrumentos y su interpretación progresiva por parte de órganos autorizados y b) la participación de la sociedad, y en particular de aquella más discriminada, en la definición de los problemas, necesidades y déficit de Derechos y en el diseño, monitoreo y evaluación de las políticas" (Gonzales Plessman, 2008, pp. 1-2).

\section{La política federal de vivienda desde un enfoque de derechos ${ }^{2}$}

La revisión de la Política Federal de Vivienda (PFV) desde un enfoque de derechos ${ }^{3}$, parte de considerar estos últimos no solo como las "Estrategias que se realizan para proteger las necesidades e intereses vitales de las personas", sino en avance hacia su comprensión como "instrumentos de transformación para lograr una mayor protección y reconocimiento de la dignidad de las personas". Ello requiere entender la política como un proceso de construcción de voluntad pública que incorpora los derechos como parte de las estrategias que un Estado debe ejercer y que relaciona las responsabilidades, obligaciones y los derechos de los sujetos sociales intervinientes con la promoción de principios y valores ${ }^{4}$ que caben a su más plena satisfacción.

Implica también la consideración de la PFV desde una mirada superadora del mero cumplimiento de las obligaciones públicas con relación al derecho a la vivienda, que incluya una perspectiva integral sobre el proceso en el que participa la política y ponga la mirada en las personas a las que se dirigen las acciones como sujetos centrales del desarrollo y del derecho. Desde allí, la mirada evaluativa observa las estrategias de inclusión instrumentadas, no solo desde la cobertura de las necesidades que la política pública provee, sino también desde dimensiones que incorporen el respeto y desarrollo de las capacidades de los involucrados y de su participación en las instituciones, las políticas y los procesos.

La Figura 1 sintetiza el modelo de relación que estructura el diagnóstico. En ella se identifica una vinculación circular iterativa entre cinco componentes que muestran las acciones de la política pública y sus resultantes. Tanto aquellas ligadas al cumplimiento de obligaciones de los

2 El marco teórico se inscribe en el enfoque de derechos promovido desde los organismos internacionales de cooperación para la formulación y evaluación de las políticas públicas. Desde este, se construye y adecúa una mirada evaluativa crítica de la acción institucional de orden público, a efectos de analizar sus avances y brechas.

3 En un enfoque de derechos humanos, los planes, las políticas y los procesos de desarrollo están anclados en un sistema de derechos y de los correspondientes deberes establecidos por el Derecho Internacional. Ello contribuye a promover la sostenibilidad de la labor de desarrollo y potenciar la capacidad de acción efectiva de la población, en especial de los grupos más marginados, para participar en la formulación de políticas y responsabilizar a quienes tienen la obligación de actuar. Cuando se formulen las políticas y los programas de desarrollo, el objetivo principal deberá ser la realización de los derechos humanos. Un enfoque basado en los derechos humanos identifica a los titulares de derechos, aquello a lo que tienen derecho, a los correspondientes titulares de deberes y las obligaciones que les incumben y procura fortalecer la capacidad de los titulares de derechos para reivindicarlos y de los titulares de deberes para cumplir sus obligaciones (Oficina del Alto Comisionado de las Naciones Unidas para Ios Derechos Humanos, 2006).

4 Visto el enfoque de derechos de forma operativa, se entiende que el objetivo del desarrollo es la plena realización de los derechos de las personas. Los principios y los valores son las vías para conseguir estos objetivos. Principios: universalidad, indivisibilidad, interdependencia, igualdad y no discriminación, participación, inalienabilidad, rendición de cuentas. Valores: dignidad, libertad, igualdad, solidaridad, seguridad, justicia (Borja Segade, García Varela e Hidalgo Lorite, 2011). 
Estados - Satisfacción y Acceso- como las referidas a las relaciones entre Estado y sociedad -Fortalecimiento de capacidades, Participación e Información-que incluyen a los sujetos participantes desde las obligaciones, responsabilidades y derechos que detentan y los procesos que los relacionan.

Los ejes Institucionalidad ${ }^{5}$, Integralidad ${ }^{6}$ y Sostenibilidad $^{7}$ transversalizan la visión de la política pública y la interpelan desde la progresividad exigible por una construcción social de pleno ejercicio de derechos.

\section{Componentes.}

\section{Contribuciones y límites}

La reflexión crítica sobre la PFV busca identificar orientaciones adoptadas y sus resultantes las contribuciones y límites que proponen a los distintos componentes ${ }^{8}$.

Desde el componente Satisfacción se observan los resultados ${ }^{9}$ cuanti-cualitativos producidos, la distribución socioterritorial y la variación de las brechas deficitarias en la cobertura de las

Figura 1.

Estrategias de inclusión. Componentes y ejes

\section{POLÍTICAS DE VIVIENDA CON ENFOQUE DE DERECHOS}

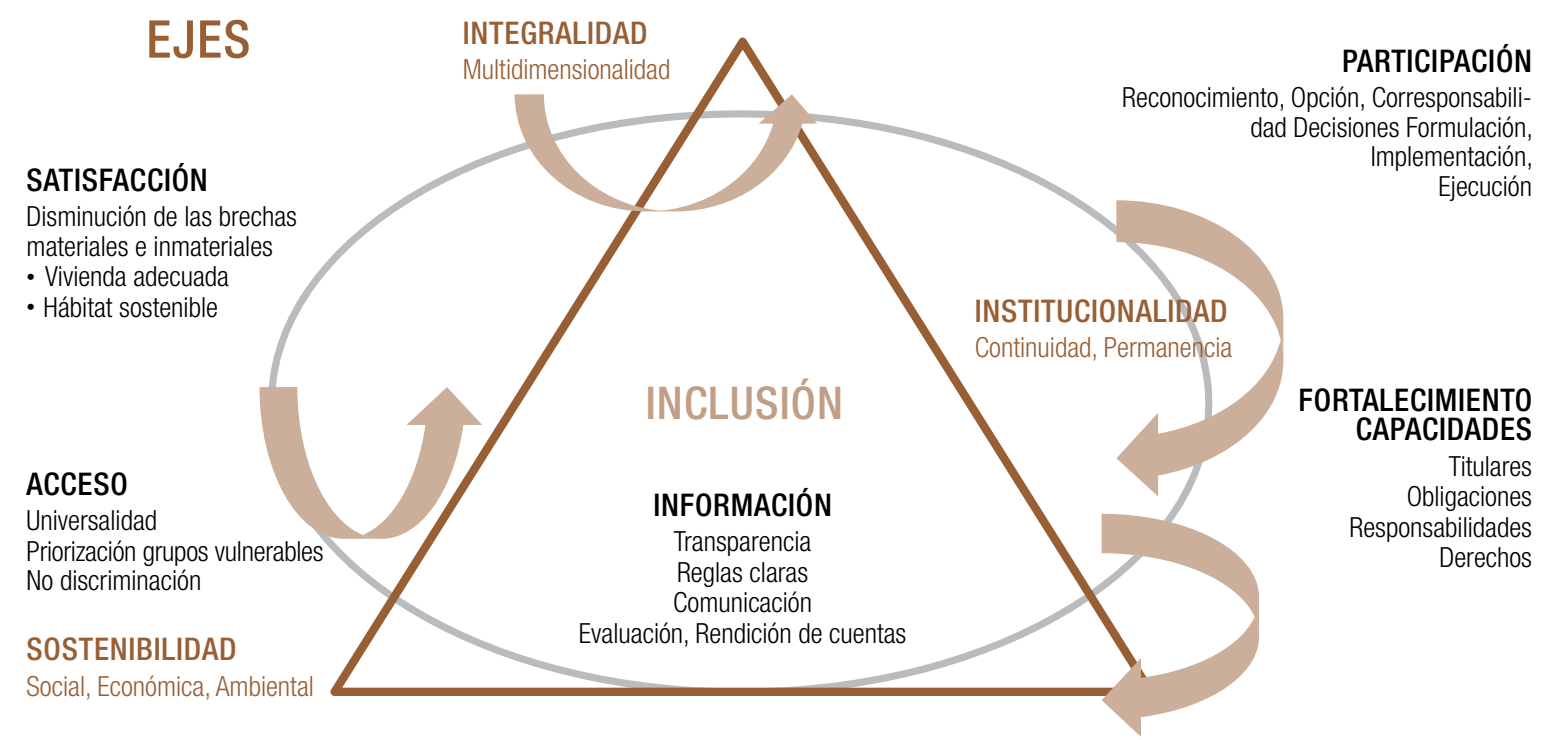

Fuente: elaboración propia

5 Institucionalidad: se relaciona con las prescripciones normativas de diverso alcance que formalizan derechos y obligaciones propias o recíprocas de los titulares de obligaciones, responsabilidades y derechos (modos de organización, procedimientos de toma de decisiones, reglas de juego rendición de cuentas, evaluación, acceso a la información, transparencia)

6 Integralidad: se refiere a la interdependencia y la indivisibilidad de los derechos con la multidimensionalidad (cobertura de las necesidades en diferentes dimensiones materiales e inmateriales, físicas, sicológicas y sociales, como el acceso a un techo — protección, seguridad, intimidad—, a la salud, a la educación y al trabajo), con la multiescalaridad (relación macro/micro, interdependencia multiescalar, etc.) y con la visión desde los actores protagonistas (participación en distintos ámbitos: privado, público, comunitario).

7 La sostenibilidad obedece a la relación entre desarrollo humano y equilibrio ambiental, sobre un escenario físico-espacial que transforma y es transformado por quienes lo habitan (Instituto Javeriano de Vivienda y Urbanismo [Injaviu], 2013).

8 La selección de componentes analíticos responde al cumplimiento de las obligaciones asumidas por los Estados para garantizar el derecho a la vivienda, en el sentido de: respetar, proteger, satisfacer e informar como elementos básicos del accionar público.

9 Indicadores de resultados. Reflejan los logros que indican el estado de realización de un derecho humano, al medir los resultados y el impacto real de estrategias, programas e intervenciones del Estado que resultan de las políticas (Borja Segade et al., 2011). 
necesidades de vivienda adecuada ${ }^{10}$ en el marco de políticas y acciones que aseguren un hábitat sostenible ${ }^{11}$ (Rodulfo y Boselli, 2013). La generación de las oportunidades de acceso por su parte, se observan desde la universalidad de sus alcances y los avances en la no discriminación por medio de la priorización de grupos vulnerables ${ }^{12}$. El involucramiento entre los actores participantes se analiza en el componente Fortalecimiento de capacidades ${ }^{13}$ (Borja Segade et al., 2011), al considerar las acciones que se realizan en cumplimiento de las obligaciones públicas de respeto, protección y garantía de los derechos en su concurrencia a fortalecer a los titulares de derechos para reivindicarlos junto con los titulares de deberes y de responsabilidades para cumplirlos. Los componentes Participación e Información refieren el análisis de las relaciones de poder y del reconocimiento público de los titulares de derechos en la toma de decisiones de las políticas y los procesos que los afectan y también las reglas de juego que se establecen, la comunicación, la rendición de cuentas y la evaluación del accionar público y su transparencia.

\section{Satisfacción}

La aplicación de la PFV a partir de 2003 dio lugar a acciones de impacto en la reactivación productiva y la generación de empleo, que contribuyó a superar la situación de emergencia socioeconómica de los inicios e instaló una renovación de las expectativas sociales y del consenso público requerido para asegurar la gobernabilidad en la poscrisis. Asimismo, creó el marco propicio para la proyección y continuidad de las acciones emprendidas en los años subsiguientes, con lo que se logró un alcance cuali-cuantitativo extendido en todo el territorio nacional con aportes significativos en la disminución del déficit relativo en las regiones más pobres del país14, aunque con baja incidencia en su índice absoluto.

La sostenida dinámica de incremento de la inversión y la producción pública dio lugar a metas sociales de satisfacción cuantitativamente crecientes, impulsadas por la diferenciación de productos habitacionales —viviendas nuevas, mejoramientos habitacionales - y la inclusión de nuevos programas y fuentes de recursos.

La inversión pública sustentada sobre fondos presupuestarios y extrapresupuestarios alcanzó los $\$ 37.800$ millones $^{15}$, para mostrar una evolución de incremento que triplicó la base de distribución del Sistema Federal de Vivienda con base en el Fonavi. Sin embargo, el crecimiento relativo verificado en la variación de los costos de producción afectados por la inflación creciente erosiona la capacidad de la PFV, dificulta el sostenimiento de las metas de producción y da lugar a la ralentización de los procesos productivos (Figura 2).

10 Atributos de la vivienda adecuada: habitabilidad, durabilidad, seguridad física y jurídica (tenencia), localización, accesibilidad económica, calidad del entorno y acceso a servicios, educación, empleo y cultura (Oficina del Alto Comisionado de las Naciones Unidas para los Derechos Humanos, 1991)

11 Se entiende por hábitat al conjunto de componentes materiales y simbólicos que operan sistémicamente como marco de producción y reproducción cotidiana de las condiciones de vida y sociabilidad (Adasko 2013). Su sostenibilidad abarca dimensiones territoriales, económicas y sociales del entorno construido.

12 Población que presenta condiciones diferenciales que la hace vulnerable a la discriminación o a la falta de igualdad.

13 Capacidades: aptitudes, cualidades y medios de los que dispone una persona para ejercer sus derechos; formas y maneras en las que cada uno de los titulares se apropia de su situación, para tener control de las circunstancias y lograr las metas propuestas, con el fin de poder cumplir con sus obligaciones, responsabilidades y derechos. Se distinguen los titulares de derechos (para que puedan ejercer sus derechos mediante el conocimiento y la apropiación de los derechos humanos y su ejercicio; los titulares de deberes o responsabilidades (familia, comunidad, organización social, instituciones, empresas y otros) para que puedan ejercer sus responsabilidades sociales y los titulares de obligaciones, que comprenden al Estado y a sus instituciones para que puedan cumplir con sus obligaciones (Borja Segade, 2011).

14 En la región nordeste del país, el déficit relativo descendió entre los dos últimos censos casi en 14 puntos (de $55 \%$ según el Censo de 2001 a $41 \%$ de hogares deficitarios respecto al total de hogares de la región según el Censo 2010).

15 Los montos mencionados corresponden a las inversiones publicadas por la Revista del Conavi expresados en valores corrientes y no incluyen otros recursos provenientes de fideicomisos de la Anses o recursos propios de las jurisdicciones. 
Figura 2.

Evolución de la inversión pública en vivienda (1990-2011)

Transferencias FONAVI + PFCV 1990-2011 (\$ valor corriente* y \$ valor constante**)

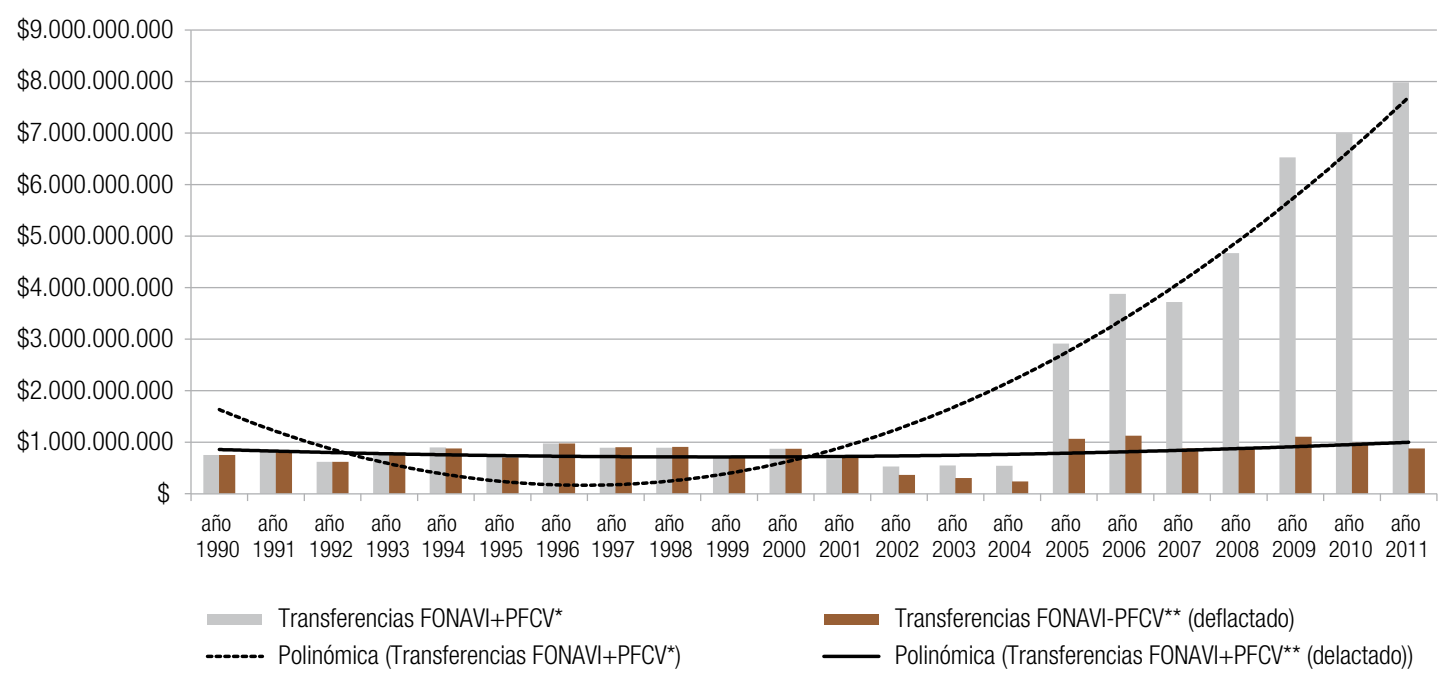

** \$ valor constante (deflactado 1993-2001 según ICC-INDEC base 100 a Dic 1993, y, a partir de 2002 segun ICC de la Cámara Argentina de la Construcción tomando Base 100 a Dic 2001)

Fuente: elaboración propia con base en Consejo Nacional de la Vivienda (2012)

Figura 3.

Evolución de la producción habitacional 1977-2011

Viviendas nuevas y Mejoramientos terminados [FONAVI y PFV] 1977-2011

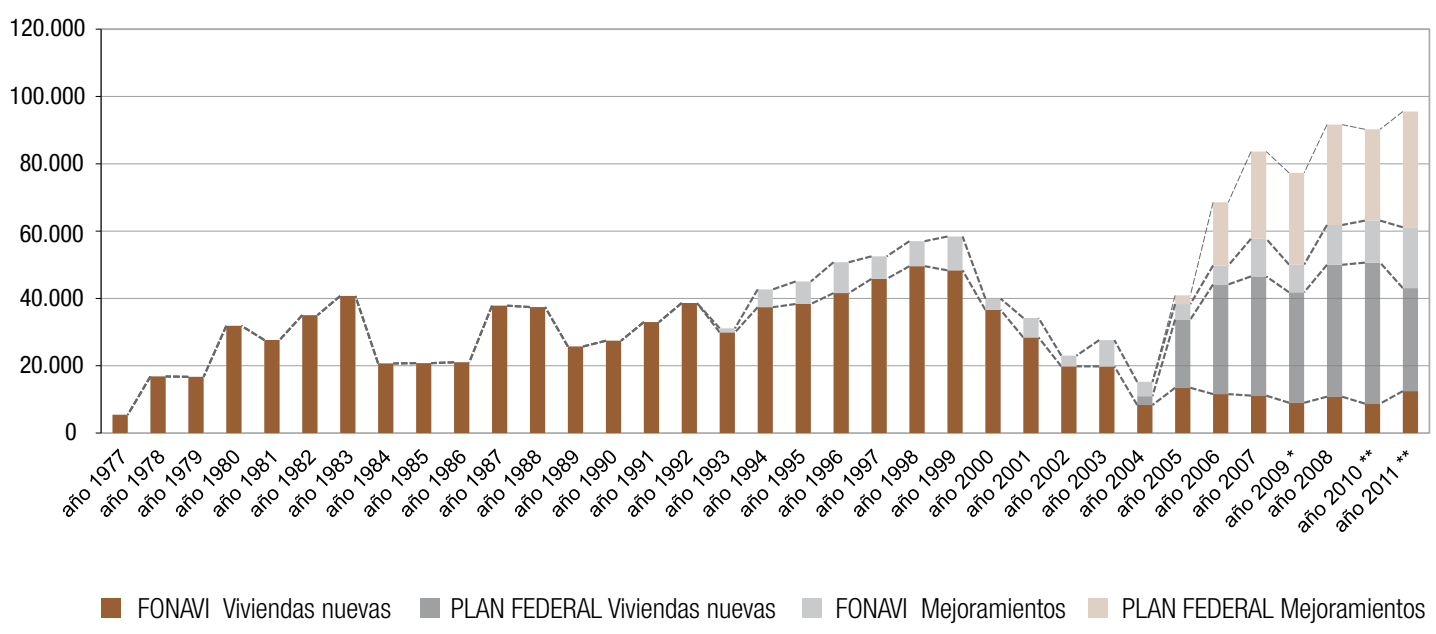

Fuente: elaboración propia con base en Consejo Nacional de la Vivienda (2012)

16 Los mejoramientos de vivienda son proyectos para resolver problemáticas específicas mediante la refacción 0 ampliación, la construcción de baños, cocina o nuevos dormitorios que permitan adecuar la vivienda a la composición del núcleo familiar para superar la condición deficitaria (Rodulfo y Boselli, 2013). 
La producción habitacional, por su parte, alcanzó las 657.007 soluciones habitacionales (351.217 viviendas nuevas y 305.790 mejoramientos habitacionales) en el período 2003-2011, con un promedio cercano a las $70.000 \mathrm{SH} / a n ̃ o$, el más alto de la actuación pública hasta la fecha (Figura 3).

El incremento de las soluciones habitacionales construidas y de las metas sociales alcanzadas se obtuvo en razón de la diversificación productiva con reemplazo de la unidad de producción de vivienda nueva por solución habitacional. Esta

Figura 4.

Diversificación de la producción comparada.

Períodos 1993/203 y 2003/2011

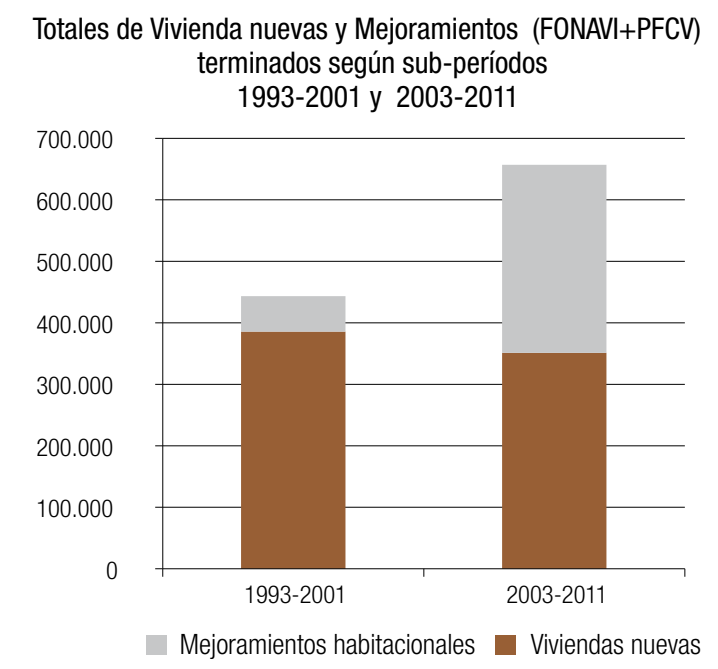

Fuente: elaboración propia unidad incluye, además de las viviendas nuevas, a las acciones de mejoramiento habitacional ${ }^{16} \mathrm{di}$ rigidas a la recuperación del parque habitacional deficitario (Figuras 4 y 5).

En términos nominales, la comparación entre dos subperíodos muestra que en el último la cantidad de unidades de viviendas nuevas terminadas (VN) registran un leve descenso, en tanto los mejoramientos habitacionales $(\mathrm{MH})$ se han más que quintuplicado a partir de la implementación de las operatorias de la PFV, que representan un $46,5 \%$ de la producción total.

Figura 5.

Operatorias de viviendas nuevas y mejoramientos habitacionales, PFV
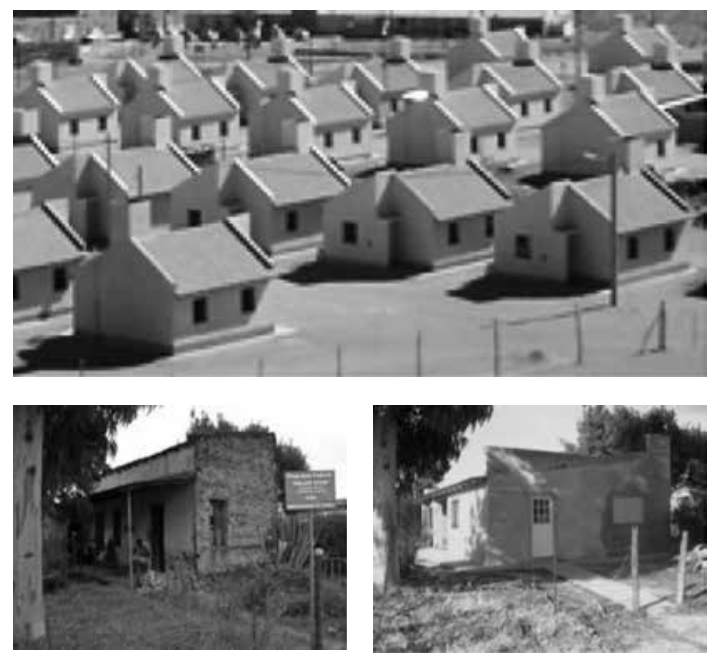

Fuente: IPV
Figura 5.1

Vivienda nueva Barrio en Andalgalá, provincia de Catamarca

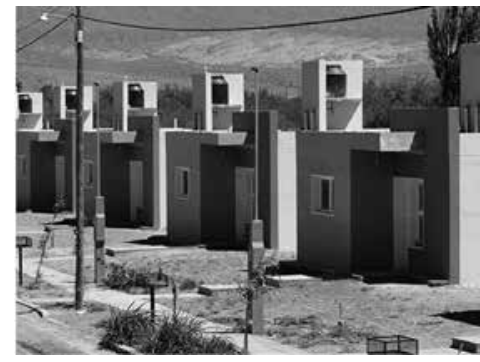

Fuente: IPV Catamarca
Figura 5.2.

Mejoramiento habitacional en provincia de Buenos Aires

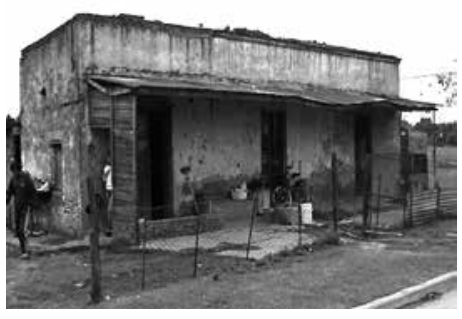

Fuente: IPV Buenos Aires
Figura 5.3.

Mejoramiento habitacional en provincia de Buenos Aires

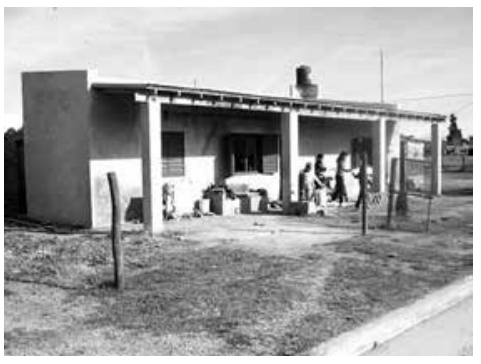

Fuente: IPV Buenos Aires 
La distribución de los mejoramientos respecto a las viviendas nuevas terminadas en las distintas jurisdicciones del país se presenta variable (mientras en Misiones representa un $80 \%$ de la producción total, en la ciudad de Buenos Aires solo alcanza un 2\%) como resultado más de los acuerdos financieros con el Gobierno central que de criterios de necesidad (Figura 6).

La producción masiva de mejoramientos habitacionales contribuye a la puesta en valor de las viviendas deficitarias recuperables, núcleo mayoritario de los requerimientos del déficit habitacional cualitativo.

La aplicación de los Estándares Mínimos de Calidad para Viviendas de Interés Social, acorde con los atributos de la vivienda adecuada, incluyen espacios apropiados para la estructura familiar, seguros, protegidos de las condiciones climáticas y otras amenazas, accesibles en términos de servicios públicos y adecuados culturalmente al habitar urbano dominante, que consolidan un parque habitacional público de 2.150 .000 soluciones habitacionales (25\% del total de viviendas no deficitarias).

Pese a la leve mejora de la situación habitacional (reducción de 0,83\% del déficit en la última década), las cifras del Censo Nacional de Población y Vivienda 2010 denotan la persistencia del déficit estructural y de los desequilibrios regionales que se mantienen a pesar del incremento sostenido de las metas sociales alcanzadas.

En las tres últimas décadas, la evolución del déficit habitacional muestra cifras de abatimiento insuficientes (4,89\% entre 1991 y 2001 y $0,83 \%$ entre 2001 y 2010) como para vislumbrar mejoras en un futuro próximo (Figura 7).

Su persistencia ofrece múltiples brechas: cerca de $50 \%$ de las viviendas del país no tienen todavía cloacas y gas; $16 \%$ de la población no puede acceder al agua de red; 444.000 personas viven en ranchos, casillas o inquilinatos; más de $4,5 \mathrm{mi}$ llones de personas dependen de una garrafa para cocinar o calentarse (ADN argentino, 2011).

Figura 6.

Distribución jurisdiccional de la producción según satisfactores

Porcentajes de Viviendas nuevas y Mejoramientos habitacionales terminados [FONAVI + PFV] según jurisdicciones - período 2003-2011

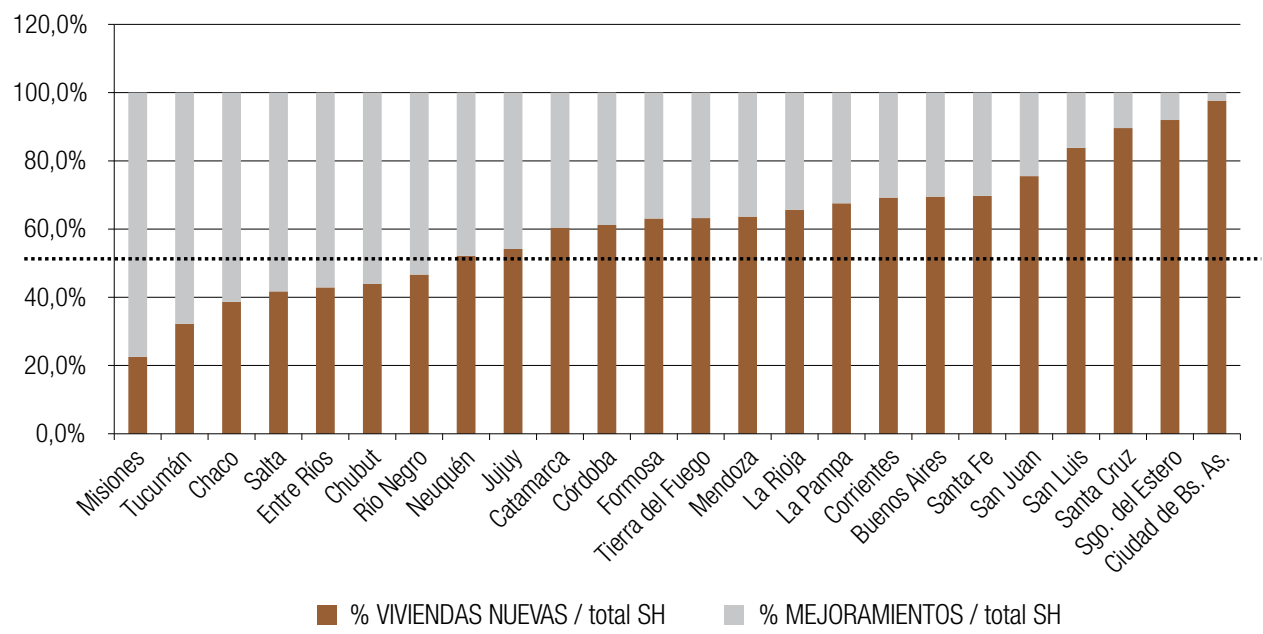

Fuente: elaboración propia con base en Consejo Nacional de la Vivienda (2012) 
Figura 7

Evolución histórica de los hogares deficitarios

Evolución del Déficit Habitacional en Argentina según Censos

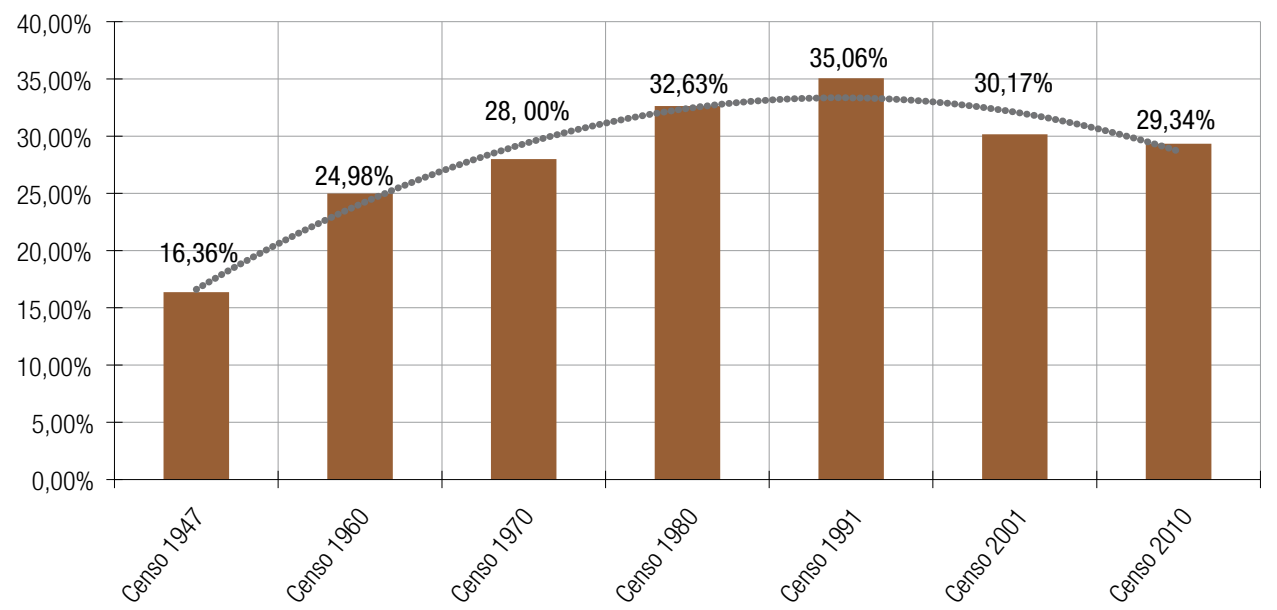

Fuente: elaboración propia

\section{Desequilibrios regionales}

El leve descenso de la situación deficitaria $(0,83 \%$ para 2010) muestra una distribución regional desigual de sus impactos relativos en el país. La región nordeste registra un descenso significativo del déficit relativo (14\%), con impacto en los índices de equidad al interior de la misma, seguida por descensos en Cuyo, Noroeste y Patagonia. Pese a la mejora, las regiones del norte del país mantienen las cuantías de déficit relativo más críticas (superiores a 40\%). Contrariamente, la región bonaerense presenta un aumento del déficit, tanto relativo $(3,8 \%)$ como absoluto $(7,1 \%)$, que se profundiza en la provincia de Buenos $\mathrm{Ai}$ res (Figura 8).

\section{Figura 8.}

Variación del déficit relativo y del déficit absoluto según regiones 2001-2010
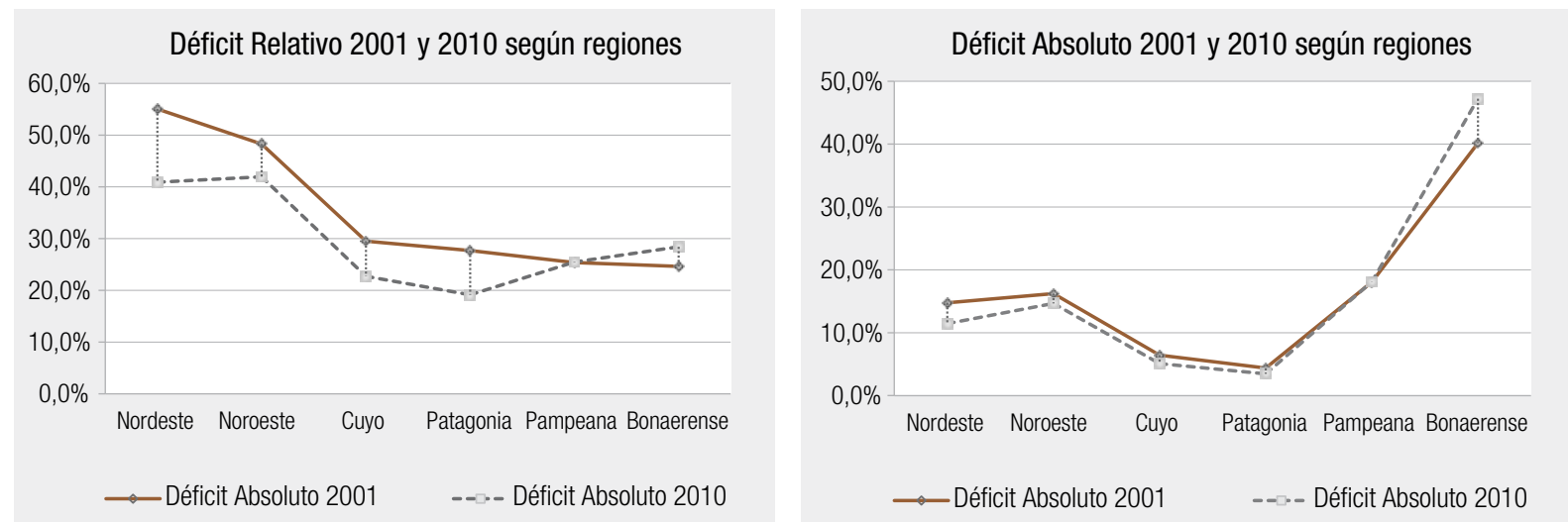

Fuente: elaboración propia 
Las desigualdades regionales dan cuenta de las dificultades presentes en el avance hacia el acceso a una vivienda adecuada y a un hábitat sostenible. A ellas se agregan las insuficiencias observadas en la selección de los emplazamientos y la adaptación al medio y los parciales incumplimientos de los Estándares Mínimos de Calidad para Viviendas de Interés Social, patologías constructivas y de diseño de las tipologías ${ }^{17}$, de corrección necesaria para elevar la calidad material del ambiente, así como la realización de las acciones conducentes a mejorar los déficits de tenencia ${ }^{18}$ (CELS, 2013), que afectan a los hogares en su capacidad de desarrollar una vida sana y segura.

El panorama regional suma interrogantes en cuanto a la eficacia de las inversiones y de los satisfactores producidos y su escasa incidencia en la variación del déficit en las jurisdicciones (Figura 9).

Figura 9.

Brechas máximas y mínimas entre inversión y producción y variación del déficit

Inversión y Producción habitaciona (2003-2011) y variación del Déficit relativo (2001.2010 según regiones

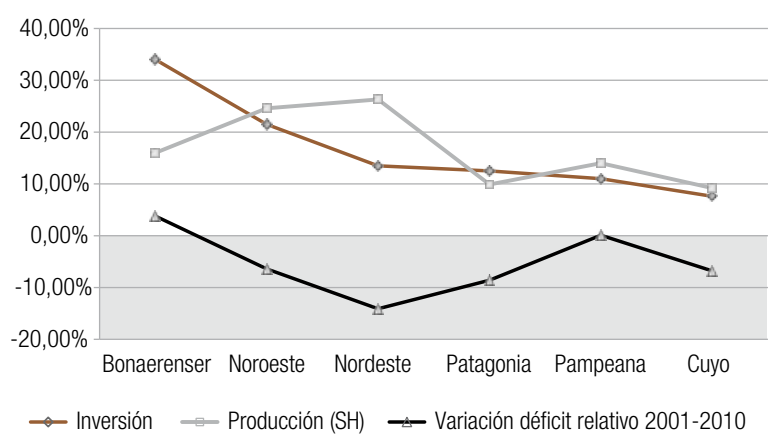

Fuente: elaboración propia

\section{Acceso}

La PFV, concentrada sobre todo en la tradicional producción por obra pública, ha mantenido una estrategia de acceso sostenida en la concepción de un Estado distribuidor de viviendas sociales, sujetas a normas y disposiciones de orden público que garantizan el acceso universal ${ }^{19} \mathrm{y}$ a la observancia de los atributos de la vivienda adecuada. En su evolución temporal ha ido incorporado modalidades de acceso diversificadas, mediante programas que activan las esferas de producción social y financiera, para avanzar en el camino de superar la fragmentación existente entre los sistemas de provisión habitacional público y privado, al proponer la ampliación de oportunidades de acceso que priorizan a los grupos vulnerables y a hogares con alguna capacidad de contribuir a superar su situación habitacional deficitaria.

Figura 10.

Esferas de producción activadas por la política

federal de vivienda

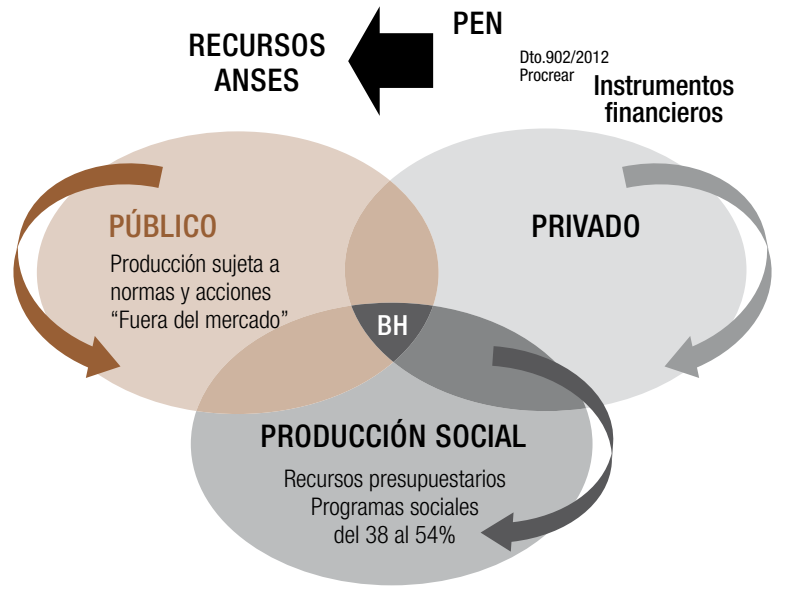

Fuente: elaboración propia

17 Puede verse Dirección Nacional de Políticas Habitacionales (2011).

18 Según un estudio del CELS, en el Censo 2010 los hogares que no son propietarios o inquilinos alcanzaron un 14,2\% (CELS, 2013, pp. 344-345).

19 La PFV ha continuado mecanismos instituidos de no discriminación incluidos hace tiempo en la instrumentación de la política pública como la consideración igualitaria — diferencias de género, raza y nacionalidad—y otras. En las últimas décadas se verificó una evolución significativa a medida que las transformaciones sociales las exigieron en el escenario de gobiernos democráticos. Las normativas han alcanzado reconocimientos y formalizaciones y se han incorporado en la implementación de las políticas habitacionales nacionales, subnacionales y locales, aunque con desiguales avances. También se han incorporado beneficios a migrantes recientes de países limítrofes, al asimilarlos a los connacionales en el acceso a la vivienda, que no están exentos del debate entre generaciones de inmigrantes amalgamados al proceso de construcción de la sociedad nacional. 
La priorización de grupos vulnerables aborda diversas estrategias, desde la protección de los hogares con miembros en discapacidad ${ }^{20}$ y los trabajadores desempleados ${ }^{21}$, así como programas sociales dirigidos a los pobladores de asentamientos precarios, comunidades aborígenes, rurales y poblaciones en situación crítica, atendidos por los movimientos y organizaciones sociales y la Iglesia (Caritas), entre otros.

La aplicación de recursos del presupuesto nacional (Área Vivienda y urbanismo) en la atención de población $\mathrm{NBI}^{22}$ se profundizó con la inclusión de nuevos programas sociales ${ }^{23}$, lo que elevó las asignaciones desde un 34,2\% (año 2008) hasta 52,7 \% (año 2012) y constituyó una ampliación de las oportunidades de acceso de los grupos vulnerables.

$\mathrm{Al}$ ampliar las oportunidades para los sectores medios con capacidad de cofinanciamiento, que desde hace más de una década no cuentan con apoyo público, el PEN ha activado una esfera de acceso al financiamiento hipotecario. Para ello, articula fideicomisos que reúnen recursos públicos (tierras del Estado nacional y subsidios de tasas de interés) y privados (aportes del sistema jubilatorio y tierras particulares) que se aplican por medio del PRO.CRE.AR ${ }^{24}$.

La progresiva ampliación de las opciones en la PFV con discriminación positiva de grupos vulnerables y otros en torno al crédito subsidiado (hogares propietarios de suelo en el Plan PRO.
Figura 11.

Operatorias sociales. Diversificación de la producción $y$ de efectores

PFC - Soluciones habitacionales terminadas a diciembre de 2011

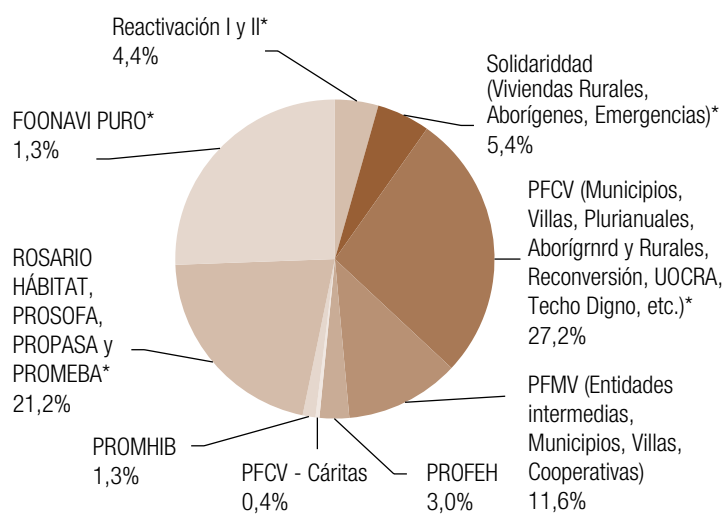

PFC - Soluciones habitacionales terminadas a diciembre de 2011

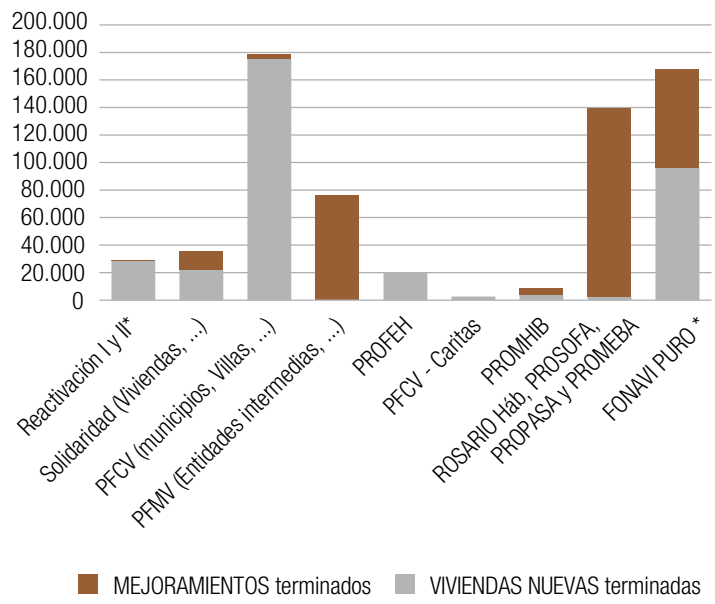

*obra pública con intervención de empresas constructoras

Fuente: elaboración propia con base en Consejo Nacional de la Vivienda (2012)

20 Obligación de destinar un 5\% de la producción de vivienda nueva a hogares con miembros en situación de discapacidad (Subsecretaría de Desarrollo Urbano y Vivienda [SSDUV], 2009)

21 La PFV incluyó como condicionante de la adjudicación de obras de construcción de viviendas sociales la obligación de incorporar una proporción de beneficiarios de subsidios para jefes de hogar desempleados. El Programa federal de emergencia habitacional "Techo y trabajo", hoy Programa 44 de integración sociocomunitaria, se dirigió a incluir trabajadores desempleados en la producción social de vivienda con base en la organización cooperativa.

22 La vulnerabilidad en estas operatorias se define por el Indicador Necesidades Básicas Insatisfechas (NBI).

23 Programa 42, Acciones para desarrollo de la infraestructura social (programas de mejoramiento de asentamientos irregulares Promeba y Rosario Hábitat y Programa social de áreas de frontera, Prosofa; Programa 44, Integración Sociocomunitaria (exemergencia); Programa 45, Programa de mejoramiento habitacional e infraestructura básica, Promhib; Programa 46, Villas y asentamientos precarios.

24 Programa de Crédito Argentino PRO.CRE.AR, recientemente creado. Financia la construcción de vivienda individual sobre terrenos de los particulares, el desarrollo de urbanizaciones en tierras fiscales con participación empresarial mediante el sistema de licitación pública y la compra de terrenos de propiedad individual o mediante empresas comercializadoras. 
CRE.AR) han recortado la universalidad del acceso del modelo anterior le han otorgado un progresivo sentido de focalización.

Como límite a las oportunidades de acceso generadas por la PFV, se verifica que, en términos cuantitativos, no alcanza a incidir en la reducción de las brechas deficitarias que afectan a los grupos priorizados.

El adosamiento sucesivo de nuevos programas sociales que se ponen en juego, sumado al insuficiente desarrollo de canales de comunicación y de procedimientos de transparencia institucionalizados, activa un deslizamiento hacia prácticas crecientemente clientelares, las que en ausencia de una evaluación de procesos y resultados, reducen la corrección de las posibles distorsiones que se acumulan, limitando los alcances de la política pública.

\section{Fortalecimiento de capacidades}

La PFV ha implementado un modelo de gestión movilizadora del sistema público que articula obligaciones y compromisos con los gobiernos subnacionales y locales. Ello extiende los alcances de las iniciativas y genera expectativas nacionales en un escenario de animación propicio al involucramiento de actores sociales, a la asociación de recursos y a los avances en el ejercicio de derechos.

\section{Respecto del fortalecimiento de las capacidades de titulares de obligaciones}

La articulación de los escenarios gubernamentales ha dado lugar al fortalecimiento de las capacidades de gestión gubernamental existentes y al aumento de la conciencia sobre las obligaciones del Estado en la cuestión habitacional (Figura 12).

La concentración de recursos en el ámbito nacional se apoyó en una doble estrategia: por una parte, la convocatoria interinstitucional al Sistema Federal de Vivienda y su órgano consultivo —Consejo Nacional de Vivienda (Conavi)_, lo que generó la legitimación necesaria para una asociación de recursos y voluntades entre los gobiernos nacional, subnacional y local. Esto dio lugar a la puesta en valor de las capacidades propias del Sistema en la construcción habitacional masiva.

Por otra parte, la convocatoria intersectorial reunió el accionar de los Ministerios de Planificación e Inversión Pública, Desarrollo Social y Trabajo, Seguridad y Empleo, en un plan común que potenció la articulación de sus recursos y se proyectó a lo largo de la década con desaprovechamiento de la integralidad potencial de sus alcances.

La progresiva subordinación dependiente de los gobiernos subnacionales y locales al gobierno central, plasmada en enlazamientos bidireccionales, se orienta hacia una toma de decisiones unipolar. La concentración de prerrogativas en el PEN en un pequeño grupo de colaboradores y en una aplicación vertical y jerárquica de los programas, determinada de "arriba hacia abajo", acentuó la discrecionalidad nacional, la dependencia subordinada y también el debilitamiento del Sistema Federal de Vivienda (Fonavi) (Figura 13).

La discrecionalidad, en parte reflejada en la adopción de criterios variables regidos por la coyuntura, la oportunidad política o la facilitación operacional, surge en perjuicio del ejercicio de la concertación democrática del régimen federal.

Muchas veces, las decisiones nacionales eluden las facultades y evaden normativas de los gobiernos subnacionales y locales y resultan coyunturalmente dilatorias. La mayor participación de gobiernos locales de afinidad política con el partido de Gobierno, en el reparto directo de recursos en función de adhesiones circunstanciales, erosionan los escenarios intermedios de gobierno (Figura 14). 
Figura 12.

Modelo de gestión inicial de la PFV. Concertación institucional y recentralización decisional

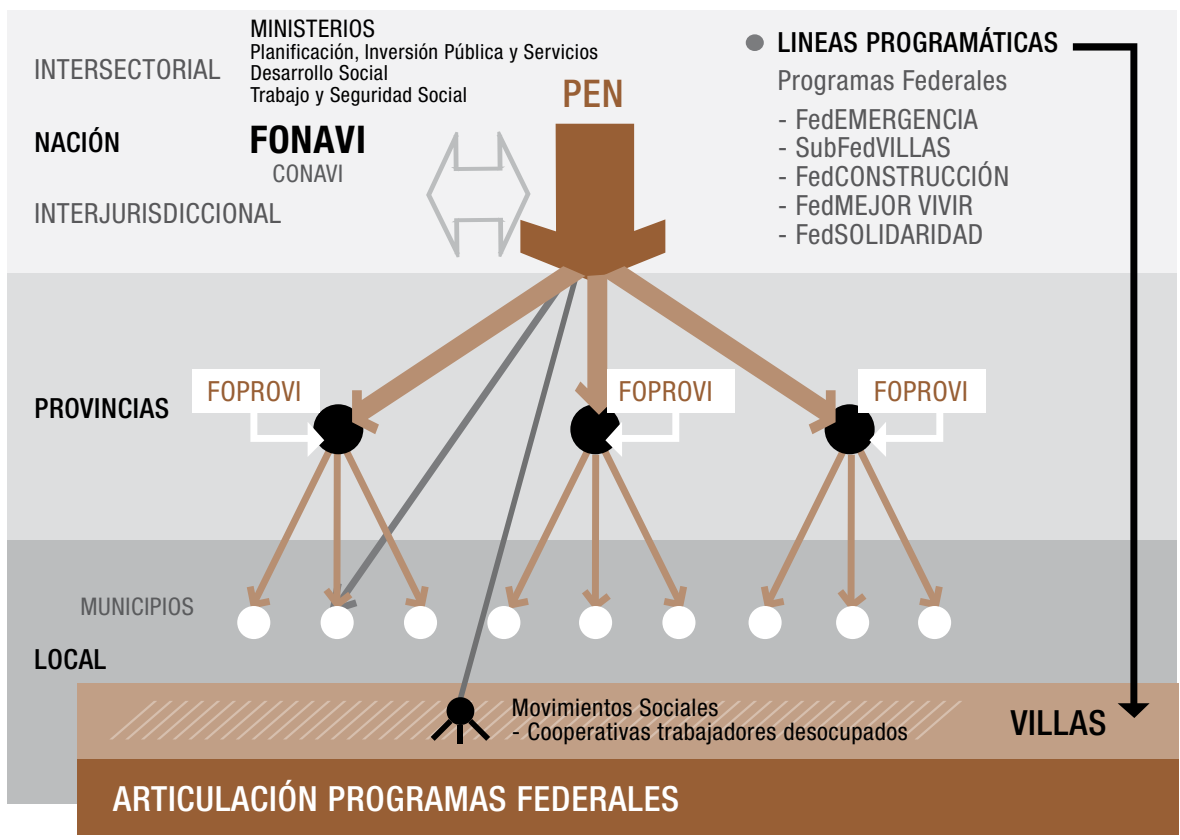

Fuente: elaboración propia

Figura 13.

Modelo de gestión actual. Concentración y subordinación unipolar de actores y decisiones

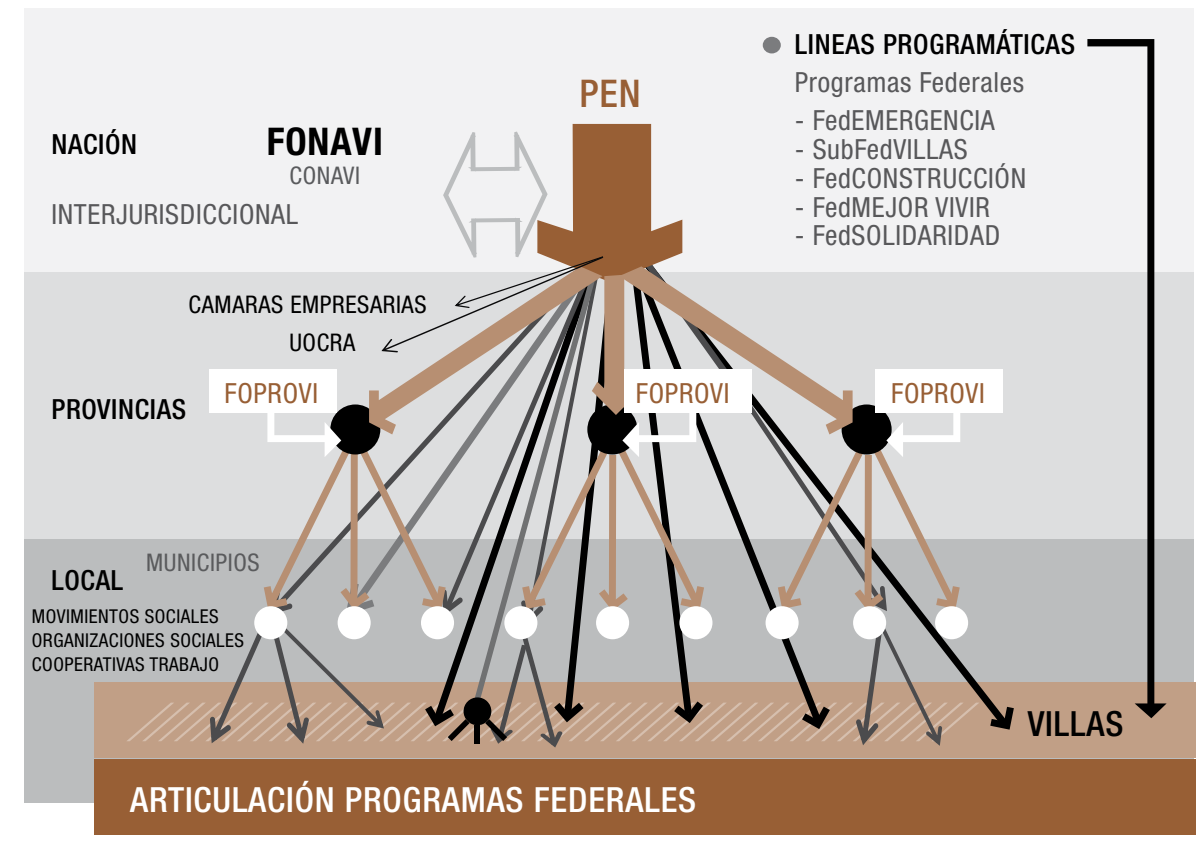

Fuente: elaboración propia 
Figura 14.

Distribución de recursos por jurisdicciones.

Relación inversión/déficit 2001

Participación en las transferencias (FONAVI+PFV) 2003-2011 con relación al Déficit absoluto según Censo 2001

Fuente: elaboración propia con base en Consejo Nacional de la Vivienda (2012)

La caída en desuso de los indicadores de desempeño inicialmente establecidos y el predominio del criterio de oportunidad y discrecionalidad vinculado a las prioridades políticas y coyunturales de Gobierno afectan la equidad distributiva, a la vez que mantienen las asimetrías históricas, al señalar ganadores y perdedores de los beneficios.

El debilitamiento del Sistema Federal de Vivienda ha acompañado esta tendencia con pérdida de su visibilidad social y trayectoria descendente de la producción Fonavi. La variación del carácter de financiamiento específico del Fonavi, potencialmente autosostenible, hacia el lugar de complemento financiero de las decisiones nacionales limita su rol como herramienta financiera descentralizada.
Así, la aplicación de mayores recursos no alcanza a compensar la ausencia de una planificación rectora y de un sistema de gestión eficiente. En este sentido, se visualizan resultantes territoriales que muestran su inequidad distributiva en las brechas de acceso entre los recursos asignados y la evolución de las necesidades, sumadas a la insuficiencia de una mirada integradora y sustentable.

\section{Respecto al fortalecimiento de las capacidades de titulares de responsabilidades}

La PFV ha convocado actores del sector de la construcción, del sector social organizado y del sector financiero para la producción del satisfactor vivienda; con ello, activa sus expectativas e intereses respecto a los apoyos públicos a obtener, en mayor medida que la habilitación de los compromisos propios o corresponsables.

Con relación al sector de la construcción, ha fortalecido los enlaces con el sector empresarial y con las organizaciones laborales sindicalizadas en el logro de los impactos plurisectoriales en las cadenas productivas. En este escenario ha reactivado y redimensionado la capacidad de estos actores de incidir en la política habitacional con aprovechamiento de las ventajas que ofrece, aunque sin proponer acciones correctivas sobre los reiterados desfases que el modelo presenta.

En este sentido, la relación entre el Estado y la producción empresarial vincula construcción de vivienda, generación de trabajo asalariado y promoción de la organización productiva mediante la obra pública. Este modelo productivo mantiene un rol constructor centrado en la esfera pública, en un círculo considerado como virtuoso o vicioso, según el ciclo de reactivación o retracción que atraviese. Implica la movilización del sector empresarial de la construcción (constructoras, fabricantes y proveedoras de insumos) y de las organizaciones laborales, como impulsoras de la producción de empleo directo e indirecto. Sus principales aportes se basan en la activación de capacidades empresariales de 


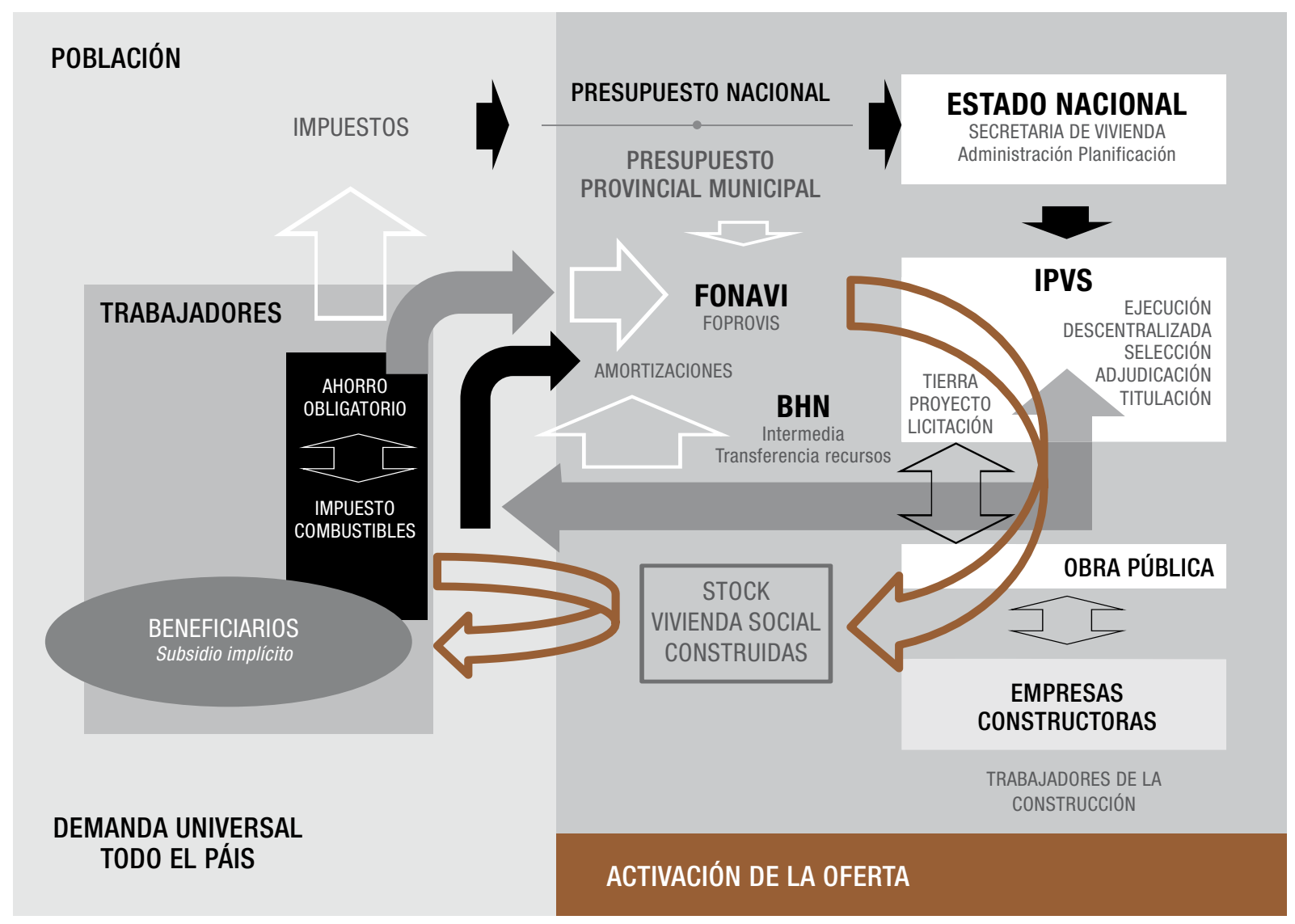

Fuente: elaboración propia

diferente escala y grado de especialización, cuya dinámica amplía la producción con efectos en metas sociales.

La ampliación y distribución territorial de la oferta de empleo, así como la mejor calificación y diversificación laboral promovida, se plasma en la alianza con las organizaciones laborales que se benefician en un contexto general de estímulos y subsidios a la producción, el consumo y la inversión.
La PFV, también ha animado la concurrencia de actores no gubernamentales, organizaciones y movimientos sociales en programas que propician la captación de capacidades de los grupos vulnerables, formación de cooperativas de trabajo y promoción de diversas modalidades productivas. Esta movilización ha dado lugar a un accionar proactivo que se abrió paso hasta incorporar sus propuestas en la agenda gubernamental, algunas de las cuales alcanzaron la institucionalidad normativa ${ }^{25}$. 
La movilización de aportes de cofinanciación por medio del crédito hipotecario (PRO.CRE. AR) involucra al Banco Hipotecario (BH SA) y a la Administración Nacional de Seguridad Social (ANSES) en la aplicación de recursos tanto a hogares beneficiarios como al sector empresarial vinculado, empresas medias y pequeñas.

Sin embargo, los avances en el desarrollo de capacidades de los titulares de responsabilidades encuentran su término en la profundización del modelo tradicional de interdependencia pública corporativo-clientelar.

Por una parte, la interdependencia del sector empresarial con el sector público limita la competitividad y eficiencia de las empresas constructoras con alto condicionamiento de las decisiones públicas. Por la otra, la relación entre organizaciones sociales y Estado recrea vinculaciones que en muchos territorios se asemejan al paternalismo feudal o alternativamente propician la dependencia de intermediarios circunstanciales ligados al partido de Gobierno o al poder local, en la apropiación de beneficios y en refuerzo del modelo clientelar.

Las cíclicas retracciones presentadas hacia el final de las décadas de activación abren interrogantes sobre la posibilidad de que la PFV configure una política de Estado capaz de superar la mera actuación coyuntural. La percepción reiterada de escenarios de presupuesto restringido que dificultan la sostenibilidad financiera con incumplimiento generalizado de compromisos públicos, la creciente necesidad de recursos para mantener la construcción de viviendas y atender las demoras emergentes, la dificultad de sostener los iniciales efectos multiplicadores de la inversión por restricciones derivadas de procesos inflacionarios y la falta de focalización en los proyectos habitacionales ante las demandas del crecimiento informal de las ciudades hacen visibles la alta concentración de beneficios en pocos destinatarios y el escaso impacto en el déficit habitacional que esta estrategia propone.
Como resultado, un escenario de incertidumbre motiva conductas especulativas y oportunistas que alejan a los titulares de responsabilidades del sano ejercicio de la responsabilidad social que les cabe y debilita su capacidad proactiva.

\section{Respecto al fortalecimiento de las capacidades de titulares de derechos}

La PFV irrumpió con extendidos alcances en el escenario habitacional para mostrar las obligaciones del Estado concurrentes en la satisfacción y acceso a la vivienda; con ello se generó una percepción positiva de los titulares de derechos que despertó expectativas sociales, aunque sin convocar a las capacidades propias de los mismos.

El fortalecimiento de capacidades se enfocó a la priorización del trabajo como variable de inclusión social. Las iniciativas desarrolladas concentraron sus esfuerzos en el desarrollo y la distribución territorial del empleo ligado al sector construcción, según variadas calificaciones. La promoción de la calificación laboral de los trabajadores de la industria de la construcción, de la mano de los convenios entre la PFV y las organizaciones sindicalizadas, fue la estrategia focalizada hacia los trabajadores desempleados. La continuidad de las operatorias sostuvo la oferta laboral a lo largo de la década, junto con la promoción de la organización cooperativa y del accionar de los movimientos sociales, que fueron los modos de canalizar la reinserción laboral de los sectores excluidos.

Como contracara, la verticalidad de programas impuestos desde el Gobierno nacional, aunada a la indefinición del perfil social de los destinatarios de la PFV, mostró una aparente ampliación de las capacidades de decisión de los gobiernos subnacionales, locales y de los efectores sociales participantes. La discrecionalidad en la aplicación de los subsidios amplió la inequidad en las asignaciones sociales. Por otra parte, la falta de reglas de juego y la imposición de viviendas y localizaciones limitó el ejercicio de la capacidad de 
opción de los titulares de derechos, lo que debilitó el cumplimiento de sus obligaciones solidarias (amortizaciones).

\section{Participación}

El reconocimiento de la participación ${ }^{26}$ como el derecho a intervenir en la definición de las políticas y, por lo tanto, en el proceso de toma de decisiones públicas aún no ha alcanzado un adecuado estatus en Argentina. Si bien el derecho a participar ha sido incluido en la Constitución nacional y en las provinciales, como instituto formal de ejercicio democrático y político, sus avances no muestran el mismo desarrollo en otros campos. La insuficiente implementación de procedimientos habilitantes en la política habitacional, en general y en la PFV, en particular, también refleja el bajo reconocimiento gubernamental de las capacidades que los actores participantes pueden aportar. Esta situación se evidencia en la inexistencia de procesos de consulta, de espacios públicos de participación social para el diseño de acciones o decisión de asignaciones presupuestarias y las escasas modificaciones normativas de la política habitacional promovidas por la sociedad civil.

La movilización del sector público, privado y comunitario, presentes en la implementación de la PFV, generó un espacio de oportunidad para la relación sociedad-Estado y posibilitó el desarrollo de vínculos de participación y de canales de información, aunque los mismos no hayan sido incluidos en el diseño.

La implementación de programas de atención de grupos vulnerables propicia el involucramiento activo de los titulares de derechos y sus organizaciones en el desarrollo de los proyectos y contribuyen a la valoración social positiva de su más plena participación ${ }^{27}$. Sin embargo, al presentarse muchas de estas vinculaciones por fuera de los procedimientos institucionalizados y como parte del ejercicio de poder de grupos con capacidad social para fijar la agenda pública o grupos "afines" que se ven convocados como parte de la sostenibilidad de las acciones de Gobierno, aparecen sombras sobre aquella valoración positiva antes mencionada. Se verifica la escasa participación racional e informada de familias, vecindarios y organizaciones sociales en las intervenciones y proyectos. Esto, en un escenario dual en el que prima el debate sobre los derechos, junto con la insuficiente difusión de reglas claras e información que faciliten su exigibilidad.

\section{Información}

La información ${ }^{28}$ relacionada con los actos de Gobierno muestra un marcado retroceso, en un escenario institucional que no ha podido consolidar canales de comunicación y sistemas de información transparentes y accesibles, lo que afecta las políticas públicas y, por ende, a la PFV.

La mayor parte de la información disponible de las acciones y los resultados de la PFV se vincula con la continuidad de los procedimientos del Sistema Federal de Vivienda y el corpus normativo Fonavi, cuyos mecanismos de control e información alcanzan las acciones en la que participan los gobiernos subnacionales. En este sentido, la existencia y continuidad de la Revista Conavi ${ }^{29}$, los procedimientos de información pública vinculados con la licitación y contratación de las obras, los registros de demanda social, de contratistas y proveedores y las adjudicaciones de viviendas, entre otros, mantienen su vigencia; en

26 Participación: construcción de una ciudadanía participativa y responsable, para conseguir una trasformación del poder que asuma una mayor vinculación de la ciudadanía en la política pública. Una mayor participación de los distintos titulares implica un mayor conocimiento e información, tanto de sus derechos como de sus obligaciones y responsabilidades; fortalece las capacidades de cada uno de ellos y genera una mayor apropiación de los objetivos que se persiguen en el proyecto (Borja Segade et al., 2011).

27 Espacio Habitar Argentina, autoconvocatoria entre organizaciones sociales y miembros del Congreso nacional (Cámara de senadores) actuantes en la formulación de cuatro proyectos de ley (una sancionada: Regularización dominial, en 2012 y tres con trámite legislativo, relacionados con vivienda y producción social del hábitat, ordenamiento territorial y regulación del procedimiento de desalojos, entre 2011 y 2012).

28 Información (comunicación) se refiere a recursos, aptitudes y habilidades que tienen las autoridades públicas para comunicarse entre sí y con los titulares de derechos y las posibilidades de acceso a los sistemas de información existentes (Borja Segade et al., 2011).

29 Revista editada por el Consejo Nacional de Vivienda de la República argentina. 
particular, se destaca la continuidad de las auditorías de control de gestión previstas en la Ley $24.464^{30}$. Asimismo, la permanencia del sitio oficial en Internet de la SSDUyV brinda información general sobre el accionar público e indica las metas de producción e iniciativas en curso, para complementar los anuncios oficiales a los medios de prensa.

No obstante, una parte significativa de las líneas programáticas de la PFV instrumentadas por adjudicación directa de proyectos y subsidios a múltiples efectores sociales no se encuentra adecuadamente informada, pues solo se cuenta con datos parciales y dispersos en los medios de difusión.

En cuanto a los mecanismos de control social pueden citarse los previstos en la Ley $24.464^{31}$, que significan un avance en materia de derechos, aunque no han sido instrumentados hasta la fecha en la administración del Fonavi ni incluidos en el accionar de la PFV; constituyen una asignatura pendiente.

La oportunidad de participación creada por la gestión pública proactiva y convocante de la $\mathrm{PFV}$ naufraga en la opacidad de información asistemática y difusa sobre los procesos de toma de decisiones y la insuficiente transparencia de la gestión financiera y presupuestaria. Ello, aunado a reglas de juego variables, ausencia de rendición pública de cuentas y de evaluación de procesos y resultados, aleja la política pública de las deseables condiciones de transparencia y acceso y afecta las opciones de los actores participantes.

La toma de decisiones, muchas veces dominada por intereses coyunturales y mediada por líderes políticos circunstanciales, condiciona el análisis de la realidad basado en datos y pruebas verificables y el debate sobre las correcciones necesarias entre las obligaciones públicas y las necesidades sociales; así, origina percepciones negativas vinculadas a la existencia de corrupción con relación al tráfico de influencias, al abuso de funciones, a la malversación o al enriquecimiento ilícito, entre otras.

En resumen, al considerar la PFV desde los componentes de un enfoque de derechos, puede decirse que las acciones realizadas ofrecen resultados que amplían las respuestas habitacionales mediante el aumento relativo de los satisfactores y de oportunidades de acceso. Dichos avances se sostienen en la movilización y el fortalecimiento de capacidades de los actores públicos vinculados y la creciente participación de actores sociales empresariales y comunitarios convocados, aunque con insuficiente ejercicio de las responsabilidades emergentes de su rol social activo.

El bajo desarrollo de la información pública, vinculada más a propagar la agenda política que a dar cuenta de la acción pública, junto con la insuficiente transparencia, evaluación y rendición de cuentas y la virtual inexistencia de canales de comunicación y de espacios de participación constituyen su principal límite.

A pesar de ello $-y$ tal vez por ello-, la dinámica desplegada por la PFV solo alcanza a estabilizar de manera parcial las brechas deficitarias estructurales en lo social y lo territorial, en un escenario en el que priman las expectativas sobre el conocimiento fundado.

\section{Estrategias de inclusión. Dilemas y desafíos}

Las estrategias de inclusión instrumentadas en la aplicación de la PFV se ven impulsadas por las contribuciones al enfoque de derechos, mientras los límites abren dilemas que interrogan 
sobre sus proyecciones futuras en dirección a las acciones necesarias. La consideración de estas cuestiones se realiza desde los ejes adoptados en el enfoque de derechos, que transversalizan la política pública como elementos inherentes a toda acción dirigida a asegurar el uso y goce de los derechos por el conjunto de la sociedad. La institucionalidad, integralidad y sostenibilidad, permiten identificar los desafíos que interpelan la proyección transformadora de sus objetivos $\mathrm{y}$ alcances.

\section{Institucionalidad}

Desde la construcción de una institucionalidad, como protección y garantía de los derechos, que permita superar el interrogante clave:

¿Gestión para el crecimiento o para el desarrollo?

¿Cómo lograr que la ampliación en la producción de satisfactores y de oportunidades de acceso contribuya en avance continuo hacia una perspectiva de desarrollo y ejercicio de derechos? ¿Puede avanzar una política habitacional que desafía la institucionalidad vigente en pos del logro de metas cuantitativas?

En este camino surgen como desafíos:

- Planificación federal concertada en la instrumentación de procesos y objetivos y mayor institucionalización de sus finalidades y procedimientos la política habitacional argentina, en su evolución histórica, nos interpela en su comportamiento pendular entre centralización nacional de las decisiones y descentralización federal con débil articulación. Los desequilibrios regionales persistentes muestran la necesidad de introducir una mayor institucionalidad de las estrategias operantes con una planificación federal concertada en la instrumentación de procesos y objetivos, que permitan que los estados subnacionales y locales y las sociedades que los integran definan prioridades y accedan a los apoyos nacionales de manera transparente y equitativa. Ello implica el objetivo de superar la inequidad distributiva y la discrecionalidad circunstancial, aislada de una perspectiva de desarrollo e inclusión social.

- Articulación y dinamización de los sistemas de provisión habitacional en una propuesta integral, que promueva el desarrollo de un marco institucional y de información pública adecuada. La fragmentación existente entre los sistemas de provisión habitacional público, privado y comunitario y el predominio de lo público con escaso diálogo entre los actores sociales involucrados proyecta la debilidad de sus articulaciones y limita la apropiación de responsabilidades de los Titulares de Derechos que debe ser superada, para dotar a la política pública de capacidad de integración potenciadora.

- Actuación pública proactiva y gestión asociada y corresponsable entre esferas de Gobierno y entre estos y las organizaciones sociales, con innovación en los procesos que prioricen la participación. Implica reconocer las capacidades de los Titulares de derechos, el respeto a la opción, la información, la organización y las singularidades culturales, sociales y territoriales. Requiere cambios en la gestión institucional que establezcan relaciones incluyentes y posibiliten espacios de participación e instrumentos habilitantes en la toma de decisiones públicas.

\section{Integralidad}

Avanzar en la naturaleza integral del derecho a la vivienda y a un hábitat sostenible plantea el interrogante:

- ¿Viviendas, soluciones habitacionales o hábitat social? ¿Debe mantenerse el enfoque sectorial centrado en la eficiente producción de satisfactores o avanzar en la ampliación de sus alcances incorporando dimensiones integrales? 
En su respuesta surgen significativos desafíos:

- Incluir la perspectiva multidimensional que sostenga una producción que mejore el producto (calidad, localización, tenencia), con participación en los procesos decisorios hacia la integralidad de las soluciones. Implica superar la visión sectorial centrada en la producción masiva de objetos - vivienda o solución habitacional- aislada de los contextos socioculturales, humanos y territoriales y pasar el foco de lo constructivo a lo social. Desde el objeto satisfactor — la vivienda o la solución habitacional- hacia el sujeto - hogar-y sus necesidades materiales e inmateriales, capacidades y derechos.

Esto es desplazar la mirada puesta en el producto para centralizar la atención en los procesos de apropiación, participación y producción e incorporar aspectos materiales e inmateriales convocados. Ello precisa dotar a la política habitacional del objetivo de contribuir a la integración social ${ }^{32}$, priorizar los grupos vulnerables y evaluar el impacto social en la calidad de vida que proveen, los aportes en la configuración de identidades territoriales y los vínculos que generan.

- Incorporar la noción de hábitat social, ampliatoria del alcance de las políticas públicas. Requiere articular las intervenciones en pos de la integración económica, social, cultural y política de los habitantes con énfasis en lo local y convocar a actores públicos privados y comunitarios. Esto hace necesario reformular el alcance territorial y social de las intervenciones y agrandar el marco de acción para: a) integrarse en el área territorial de asentamiento, sea región, paraje, barrio o ciudad, mediante la rehabilitación de infraestructuras, la reconversión de tejidos urbanos ociosos, la reurbanización de asentamientos de pobreza y la generación de trabajo e ingresos, con inserción en acciones desarrollo humano y protección social; b) crear condiciones de tenencia segura e innovar en mecanismos registrales que hagan expeditiva la relación entre las dinámicas sociales, la formalización documental y los costos de actualización.

\section{Sostenibilidad}

La sostenibilidad se construye en torno a la relación entre desarrollo humano, equilibrio ambiental y la posibilidad efectiva de continuidad temporal de las prácticas, sin afectación o perjuicio de los derechos de las generaciones futuras.

Avanzar en la sostenibilidad de la política pública superando los condicionamientos territoriales, económicos, financieros y sociales plantea el interrogante:

- ¿Activación de la oferta o activación de la demanda? ¿Puede sostenerse la inversión creciente y la producción masiva dependiente del Estado y resolver las expectativas y el déficit acumulado sin la participación corresponsable de la demanda?

La respuesta plantea los siguientes desafíos:

- Asegurar la calidad adecuada para un hábitat sostenible (durabilidad, habitabilidad y seguridad), ampliar las oportunidades de acceso al suelo urbanizado y promover instrumentos y estrategias para la producción social del hábitat, la apropiación social y la tenencia segura de la vivienda. Implica el cumplimiento de las normas y Estándares Mínimos de Habitabilidad, el uso de materiales nobles en la construcción de las soluciones habitacionales, la elección adecuada de las localizaciones y la participación efectiva de los hogares organizados, entre otros.

32 Integración social: situación meta en la que los miembros de los hogares (cualquiera que sea su condición de edad, género o etnia) estén insertos dentro del sistema formal de la economía (en condición activa o pasiva) y tengan garantizado el acceso a los servicios sociales esenciales, de salud, educación, seguridad, cultura, recreación, etc., de manera aceptable con relación a las condiciones generales de la sociedad de pertenencia; hace necesario apostar al esfuerzo del hogar y valorar su capacidad de autogestión con apoyos. 
- Adoptar mecanismos que aseguren la equidad y transparencia en la distribución de recursos y subsidios nacionales con movilización de variadas fuentes de recursos económicos, en su más amplio espectro. Requiere la inclusión de alternativas que recuperen la solidaridad social en avance hacia el necesario reintegro de los recursos públicos, la canalización de ahorros y esfuerzos y el fortalecimiento de procesos autogestionarios y de economía solidaria con el empeño puesto en la promoción de contextos previsibles y estables.

- Generar escenarios donde los ciudadanos puedan ejercer sus derechos sobre el control social de procesos y resultados. Precisa la creación y el refuerzo de espacios participativos y canales de comunicación (sociedad-gobiernos) en los distintos escenarios de actuación, que aseguren la transparencia y una acción abierta a la actuación protagonista de los sectores sociales convocados.

\section{Reflexiones finales}

Más allá de las cifras y de las observaciones, el contexto actual impone a la política pública la problemática integral del hábitat y sus concepciones en el abordaje de las emergentes y agudas demandas sociales y los nuevos procesos socioterritoriales y económicos.

Surge el desafío de superar el mero crecimiento y transformarlo en desarrollo. Ello requiere del Estado una actitud transformadora en el abordaje de los retos que lo interpelan, junto con la mayor eficiencia de un sistema público convocante de la participación del cuerpo social que, a la par, asegure el aumento de las oportunidades de acceso, la transparencia y equidad de los mecanismos distributivos y el imprescindible control social de los beneficios sociales producidos.

Este desafío también requiere que la conducta pública refuerce el cumplimiento de las obligaciones asumidas por los Estados para garantizar el derecho a la vivienda, en el sentido de respetar las formas de satisfacción habitacional desarrolladas por las comunidades que faciliten la autoayuda de los necesitados y los modos de abstenerse de realizar prácticas que violenten dichos esfuerzos; proteger frente a posibles intervenciones arbitrarias de terceros en el goce del derecho a la vivienda; satisfacer el acceso a la vivienda adecuada e informar como elemento indispensable al ejercicio de participación, como garantía final del derecho.

\section{Bibliografía}

Adaszko, D., Donza, E., Musante, B., Rodríguez Espínola, S., Turchetti, P., Salvia, A. y Suárez, A. de J. (2011). Deudas y progresos sociales en un pais que hace frente a su bicentenario. Argentina 2004-2010. Recuperado de http://bibliotecadigital.uca.edu.ar/repositorio/investigacion/deudas-progresos-sociales-pais-bicentenario.pdf

ADN argentino (2011). Información sobre datos resultantes del Censo 2010. Recuperado de http:// www.adnarg.com.ar

Borja Segade, C., García Varela, P. e Hidalgo Lorite, R. (2011). Enfoque basado en derechos humanos: evaluación e indicadores. Recuperado de http://www.redenderechos.org/webdav/publico/ evaluacionEBDH_final.pdf

Boselli, T. y Rodulfo, M. B. (22 de septiembre de 2011). La politica federal de vivienda, crecimiento sectorial vs. debilitamiento socio-institucional. Conferencia presentada en 2 do. Congreso internacional de vivienda social. Córdoba, FAUDI, Universidad Nacional de Córdoba.

Capello, M. y Galassi, G. (2011). Problemas habitacionales e inversión en viviendas sociales en Argentina. Monitor Fiscal, Año 6 (19). Recuperado de http://www.ieral.org/images_db/noticias_archivos/1856.pdf 
Centro de Estudios Legales y Sociales [CELS] (2013). Vivienda adecuada y déficit habitacional. Intervenciones complejas y necesarias. Recuperado de http://www.cels.org.ar/common/documentos/Cap.\%204\%20(DESC)\%20CELS.\%20Informe\%202013.pdf

Congreso de la Nación Argentina (1972). Ley 19.929, "Creación del Fondo Nacional de la Vivienda". Recuperado de www.infoleg.mecon.gov. ar/infolegInternet

Congreso de la Nación Argentina (1977). Ley 21.581, "Fondo Nacional de la Vivienda". Buenos Aires: Boletín Oficial 23672, junio 2 de 1977. Recuperado de http://infoleg.mecon.gov.ar/infolegInternet/verNorma.do?id=30932

Congreso de la Nación Argentina (1980). Ley 22.293, "Jubilaciones y pensiones contribuciones patronales". Buenos Aires: Boletin Oficial 24517, octubre 6 de 1980. Recuperado de http:// infoleg.mecon.gov.ar/infolegInternet/verNorma. do? $\mathrm{id}=180328$

Congreso de la Nación Argentina (1989). Ley 23.696, "Reforma del estado emergencia administrativa”. Buenos Aires: Boletín Oficial 26702, agosto 17 de 1989. Recuperado de http://infoleg.mecon.gov.ar/infolegInternet/verNorma. do?id $=98$

Congreso de la Nación Argentina (1991). Ley 23.966, "Impuestos, previsión social combustibles, gas natural, jubilaciones especiales". Buenos Aires: Boletin Oficial 27201, agosto 1 de 1991. Recuperado de http://infoleg.mecon.gov.ar/infolegInternet/verNorma.do?id=365

Congreso de la Nación Argentina (1992). Ley 24130, "Impuestos. Acuerdo entre el Gobierno nacional y los provinciales". Buenos Aires: Boletín Oficial 26702, septiembre 2 de 1992. Recuperado de http://infoleg.mecon.gov.ar/infolegInternet/anexos/0-4999/17/norma.htm
Congreso de la Nación Argentina (1992). Ley 24464, "Sistema Federal de la Vivienda. Su creación". Buenos Aires: Boletin Oficial 28117, marzo 8 de 1995. Recuperado de http://infoleg.mecon.gov. ar/infolegInternet/anexos/15000-19999/16331/ norma.htm

Congreso de la Nación Argentina (1992). Ley 25570, "Acuerdos. Coparticipación federal de impuestos. Bases". Buenos Aires: Boletin Oficial 29891, abril 10 de 2002. Recuperado de http://infoleg.mecon.gov.ar/infolegInternet/anexos/70000-74999/74031/norma.htm

Congreso de la Nación Argentina (2007). Ley 26337, "Presupuesto general de la Administración nacional. Ejercicio 2008”. Buenos Aires: Boletin Oficial 31312, diciembre 28 de 2007. Recuperado de http://www.infoleg.gov.ar/infolegInternet/verNorma.do?id=136187

Congreso de la Nación Argentina (2008). Ley 26422, "Presupuesto general de la Administración nacional. Ejercicio 2009”. Buenos Aires: Boletin Oficial 31537, noviembre 21 de 2008. http://www.infoleg.gob.ar/infolegInternet/anexos/145000-149999/147502/norma.htm

Congreso de la Nación Argentina (2009). Ley 26546, "Presupuesto general de la Administración nacional. Ejercicio 2010". Buenos Aires: Boletin Oficial 31790, noviembre 21 de 2008. Recuperado de http://www.infoleg.gob.ar/infolegInternet/anexos/160000-164999/160781/ norma.htm

Congreso de la Nación Argentina (2012). Ley 26784, "Presupuesto general de la Administración nacional. Ejercicio 2013". Buenos Aires: Boletin Oficial 32515, noviembre 5 de 2012. Recuperado de http://www.infoleg.gob.ar/infolegInternet/anexos/200000-204999/204228/norma.htm

Consejo Nacional de la Vivienda [Conavi] (abril de 2012). Estado de avance de los Programas Federales y Fonavi al 31/12/2011. Revista del 
Consejo Nacional de la Vivienda de la República Argentina (36), 58-62.

Dirección Nacional de Políticas Habitacionales (2009). Informe de Auditorias FO.NA. VI y Programas Federales. Ejercicio 2008. Recuperado de www.vivienda.gob.arldocestadisticas.php

Dirección Nacional de Políticas Habitacionales (2011). Informe de Auditorias FO.NA. VI y Programas Federales. Ejercicio 2010. Recuperado de www.vivienda.gob.arldocestadisticas.php

Gonzales Plessman, A. J. (2008). Politicas públicas con enfoque de derechos humanos: una propuesta para su conceptualización. Recuperado de http:// repositorio.uasb.edu.ec/bitstream/10644/1022/1/ RAA-23-Gonz\%C3\%A1lez-Pol\%C3\%ADticas $\% 20 \mathrm{p} \% \mathrm{C} 3 \%$ BAblicas $\% 20$ con\%20enfoque\%20de\%20derechos\%20humanos.pdf

Instituto Javeriano de Vivienda y Urbanismo [Injaviu] (2013). Convocatoria Coloquio "Vivienda, Ciudad y Territorio en América Latina: Cambios y continuidades en los últimos 20 años". Recuperado de http://puj-portal.javeriana.edu.co/ portal/page/portal/Facultad\%20de\%20Arquitectura\%20y\%20Diseno/ins_injaviu_coloquio

Lépore, E. y Pierre, A. (s. f.). Informe técnico sobre la situación de la vivienda en Argentina. Recuperado de http://www.uca.edu.ar/uca/common/ grupo68/files/informe_vivienda_dsa03-2004.pdf

Oficina del Alto Comisionado de las Naciones Unidas para los Derechos Humanos (2006). Preguntas frecuentes sobre el enfoque de derechos humanos en la cooperación para el desarrollo. Nueva York y Ginebra: Naciones Unidas.

Oficina del Alto Comisionado de las Naciones Unidas para los Derechos Humanos (1991). El derecho a una vivienda adecuada (Art.11, párr. 1): 13/12/91. Recuperado de http://www.acnur.org/ biblioteca/pdf/3594.pdf?view=1

Rodulfo, M. B. (2010). Política habitacional. La lógica de los actores y la dinámica de los programas en la post crisis. En Ortecho, E., Peyloubet, P. y De Salvo, L. (comps.), Ciencia y tecnología para el hábitat popular (pp. 127-139). Buenos Aires: Nobuko.

Rodulfo, M. B. y Boselli, T. (2013). Dilemas y desafios de la politica habitacional argentina en la segunda década del siglo XXI. Conferencia presentada en Coloquio Injaviu 2013. Mesa temática "Vivienda, inclusión socialy derechos humanos". Bogotá D. C., Instituto Javeriano de Vivienda y Urbanismo (Injaviu), Pontificia Universidad Javeriana.

Rodulfo, M. B. y Boselli, T. (en prensa). ¿Quo vadis Fonavi? Una perspectiva de la política habitacional en Argentina. En Red de Estudios sobre Política Habitacional Argentina (EPHA) (ed.), Observatorio de la política habitacional de Argentina. Buenos Aires: Café de las Ciudades.

Subsecretaría de Desarrollo Urbano y Vivienda [SSDUV] (2002). Diagnóstico de la situación habitacional urbana, 2001. Recuperado de http:// www.vivienda.gov.ar/docestadisticas.php

Subsecretaría de Desarrollo Urbano y Vivienda [SSDUV] (2006). Informe sobre la caracterización urbano-habitacional en la Argentina. Año 2006 y Evolución 2001-2006. Recuperado de www.vivienda.gov.ar

Subsecretaría de Desarrollo Urbano y Vivienda [SSDUV] (2009). Reglamento particular Programa federal de construcción de viviendas-Techo Digno. Recuperado de http://www.vivienda.gob. ar/construccion/normativa.html

Subsecretaría de Desarrollo Urbano y Vivienda [SSDUV] (marzo-abril 2010). Gestión obras públicas 2003-2009. Boletín Proyecto Urbano (18), 5 .

Subsecretaría de Desarrollo Urbano y Vivienda [SSDUV] (s. f.). Estándares Minimos de Calidad para Viviendas de Interés Social. Recuperado de http://www.vivienda.gob.ar/documentos/legislacion_y_normativa/estandaresminimos.pdf 